\title{
Green economy - a promising environment for innovative entrepreneurship
}

\author{
Madina Tulegenova ${ }^{1}$, Aifer Baimukhametova ${ }^{1 *}$ \\ ${ }^{1}$ Al-Farabi Kazakh National University, 050040 Almaty, Republic of Kazakhstan
}

\begin{abstract}
The process of technological transformation proceeds continuously, embodying new knowledge in new technologies and products. Each of its stages gives rise to a new model of entrepreneurship and human economic behavior. In the course of his active life, man transforms the natural environment to meet his needs. But showing excessive selfishness, he crossed the critical threshold of intervention in wildlife, causing irreparable damage. Industrial technology has accelerated this process. There is a need to change the model of economic and environmental business behavior as the basis for sustainable development. The formation of a new environmental culture begins in the field of education and is implemented in entrepreneurial activity.
\end{abstract}

\section{Introduction}

Man is a part of wildlife and its product. The material basis for the development of mankind is the process of natural resources appropriation and processing. As soon as man learned to make fire, the relationship between man and nature began to build on the dominance of man over nature. Since then, exhausting, polluting and destroying the riches of nature, man condemns himself to intensifying natural disasters, frequent economic crises.

The structure of natural capital is diverse and determines the degree of competitive opportunities for business and the national economy as a whole. Until recently, it was believed that the richer the state's natural reserves, the higher its level of competitiveness. However, the commercial interests of economic entities lead to the depletion of its irreproducible part, undermining the stability of both individual countries and the world economy.

By reproducing a model of economic growth due to the excess profits from the sale of natural reserves, increasing productivity in agriculture, using pesticides, many states have achieved overproduction of consumer goods. At the same time, in countries of the developing market, the quality of human life is getting worse, which is manifested in the decrease of the young generation life expectancy, and health deterioration of the population.

\footnotetext{
${ }^{*}$ Corresponding author: aifer-@mail.ru
} 
The task of mankind is to reduce the use of limited natural resources, replacing them with renewable natural sources of energy. This task will be solved by entrepreneurs who are able to rebuild production by creating and using resource-saving technologies, developing an ecological business culture.

\section{Scientific heritage and modern theory of sustainable development}

The negative consequences of aggressive human behavior in relation to the nature have become the subject of active research in the middle of the last century in the scientific world. The impetus to this process was given by the consequences of the atomic bomb use in Japan, where people died, radiation sickness claimed hundreds of thousands lives, and the surrounding nature was destroyed for many years. In the same years, similar phenomena were observed at the Kazakh and Russian nuclear test sites. The changes in Nature and Man have become the object of study not only for branch sciences, but also for interdisciplinary research.

Researchers find the sources of scientific thought about the unity and contradictions of Man and Nature in the teachings of the Russian academician V.I. Vernadsky who is the founder of the noosphere concept, the natural habitat of mankind, in which the forces of nature and man accumulate. According to the theory of V.I. Vernadsky, the natural source of human life is solar energy, which turns into the biochemical energy of living matter, concentrated in natural wealth. The biosphere is naturally created for the life and development of a man.

According to his definition, the biosphere is the natural environment, the pristine shell of the Earth, transforming solar energy into terrestrial energy: electrical, chemical, mechanical, thermal [1]. A person transforms the biosphere into a noosphere in the course of his active economic activity, which is a shell of the globe, saturated with a person's energy, thoughts and actions.

According to the theory of V.I. Vernadsky, information and social energy is formed and accumulated in the noosphere. The Consciousness of Man and society is formed by information and energy flows that materialize in the abilities of people, in a behavior culture.

In addition, the noosphere provides feedback from nature to society. The reaction of this environment depends on human behavior, on how sensitive it is to nature.

Bioenergy is directed to the construction of the future with a positive energy field created by the useful work of man and reason in the form of industry, infrastructure, science, high culture. With the aggressive behavior of society, the noosphere directs energy flows to the destruction of the present and future.

Before V.I. Vernadsky's teachings of human behavior norms fragmentary interpretations in nature and economy, his selfish interests can be found in papers of ancient thinker's, philosopher's and early economist's. For example, in the book of Milton Myers, "The Soul of a Modern Economic Man," the expression of the English philosopher T. Hobbes is given: people's interest is “... the most powerful and most destructive human passion" [2].

The founder of classical political economy, A. Smith wrote, the nature of man is determined by his own interest and selfishness, "the same among all people, an enduring desire to improve their position" [3].

The economic interest of the individual, society, the followers of the classical school and representatives of other nascent scientific schools of economists were studied in the framework of theology, from the standpoint of the deification of natural forces by man. The level of human development has not yet allowed him to exploit natural factors. The balance between society and nature in pre-industrial periods was maintained. 
In the industrial era, scientific research is related to finding a problems solution caused by growing imbalances that threaten the sustainability of human development: in the growth rate of production and consumption, in the distribution of resources and income, in the number of elderly and young generations of the Earth's population. The greatest risks to the sustainability of development are associated with increased consumption of human development and the depletion of limited natural resources, the deterioration of the biosphere situation in the post-industrial period.

The global impact of the growing environmental crisis began to require states authorities and international organizations intervention.

In 1970, on the initiative and financial support of the Rome Club, a group of scientists from around the world, conducted a study and prepared the scientific project "Limits of Growth. Report to the Rome Club" under the scientific supervision of professor Jay Forrester and his student Denis Meadows, Massachusetts Institute of Technology. The authors of the report concluded that if current trends in population growth, industrialization, environmental pollution, food production and resource depletion continue, then over the next century the world will approach limits of growth, an unexpected and uncontrolled decline in population will occur, and the production volume will drop sharply.

However, they believed that it was possible to change growth trends and come to long-term sustainable economic and environmental stability. And this state of global equilibrium must be established at a level that will satisfy the basic material needs of each person and give everyone equal opportunities to realize their personal potential [4].

The results of the study showed that while maintaining the growth model through the exploitation of natural resources, new generations of the near future will achieve a demographic and economic collapse, which will lead the system to a global catastrophe. Scientists justified the need to build a new model of human development, which was called the paradigm of "Sustainable Development". The peculiarity of this development model is that economic growth at each stage is accompanied by a reduction in non-reproducible resources.

\section{Technological progress, environmental damage and the sustainability of emerging market economies}

The 19-th century industrial revolution, laying the foundation for a new round of technological progress, became the initial factor in the depletion of natural resources, environmental pollution and the cyclical nature of economic development.

The perception of nature and its resources as the main factor of production grew in society as production expanded in the pursuit of profit. However, such an economic approach violates the global economic equilibrium. This is evidenced by energy crises: for the first time plunged the world economy into financial collapse in 1973-1974, when the OPEC consortium created by oil-producing Arab countries reduced oil sales by $10 \%$. As a result, prices per barrel of Brend oil in the world market rose from $\$ 3$ to $\$ 12$. In subsequent years, oil prices rose, and in mid-2008 reached a maximum of $\$ 150$ per barrel. Price increases occurred as a market reaction to geopolitical problems, the volatility of global financial markets. In our opinion, the main factor behind the rise in hydrocarbon prices was the increase in production volumes oriented towards satisfying the demand of the "consumer society" with a low environmental culture.

The expansion of production for the sake of saturating the immense market has led to the fact that environmental pollution with production waste, saturation of the soil with pesticides led to disruption of biological processes in the animal organism, in the plants structure. Accordingly, the content of livestock and agricultural products has changed, that is negatively affects the health of the population. 
The processing of municipal solid waste is another acute environmental problem on the path to the development of a green economy in the Republic of Kazakhstan. As of January 1, 2019, 100 million tons of garbage are already stored in landfills, most of which do not comply with sanitary control standards according to experts. Only 10 percent of the total waste is recycled, the rest is to be disposed. The poorly growing business in the field of waste management is explained by low tariffs for waste processing, the lack of state support and a centralized system for the collection, sorting and processing of waste.

According to German Institute of Economics researchers, Germany became the leader in recycling on the territory of European Union, where waste is not only recycled, but also returned to useful circulation with a share of 66 percent. One of the main achievements of European countries is the generation of energy through incinerators. Disposal of garbage in the territory of European countries is an established process [5].

The Republic of Kazakhstan, following the path of countries with a catch-up economy, has a predominantly raw material economic focus with a high share of natural resource expenditures and air pollutant emissions.

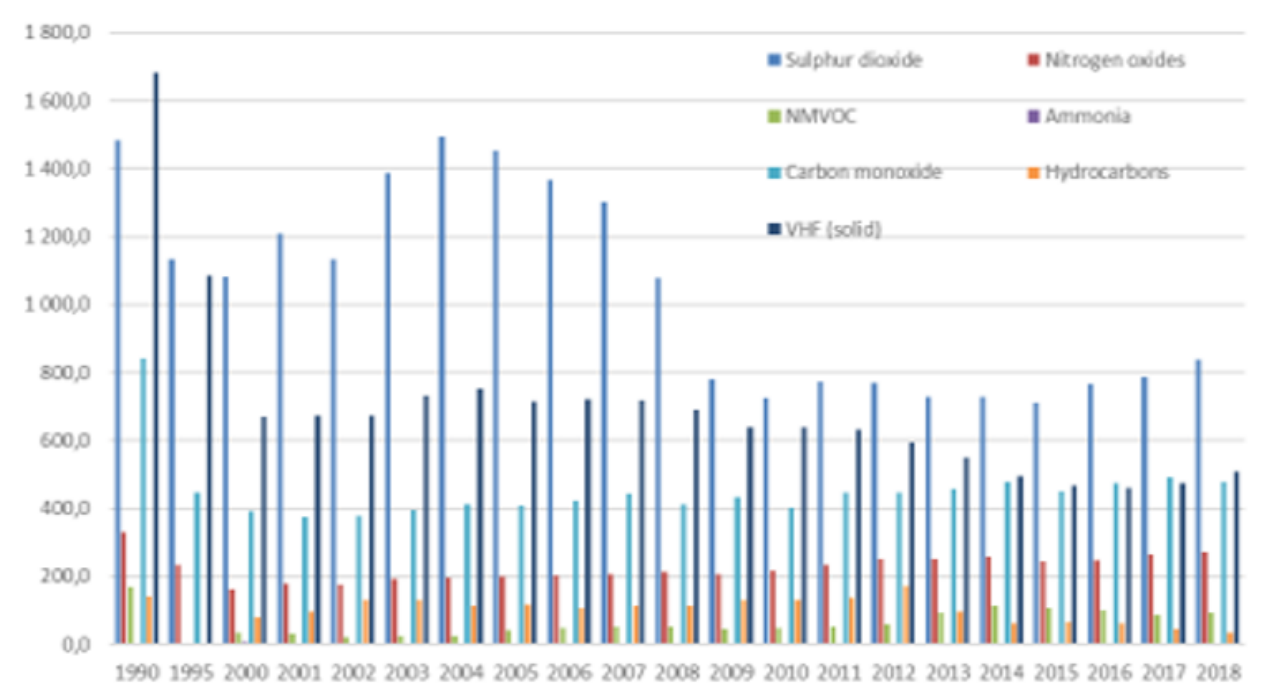

Fig 1. Composition of pollutants into the air.

From figure 1 we can conclude that sulfur dioxide and VHF (solid) predominate in the total volume of air polluting substances. Over a period of 17 years, the share of emissions of these substances has halved, but still exceeds the allowable threshold. Oversaturation of sulfur dioxide in the atmosphere adversely affects the human body, causing chronic lung disease and leaching of vitamins from the body. The environmental impact of this substance is also significant. Sulfur dioxide can cause acid rain, which can cause heavy

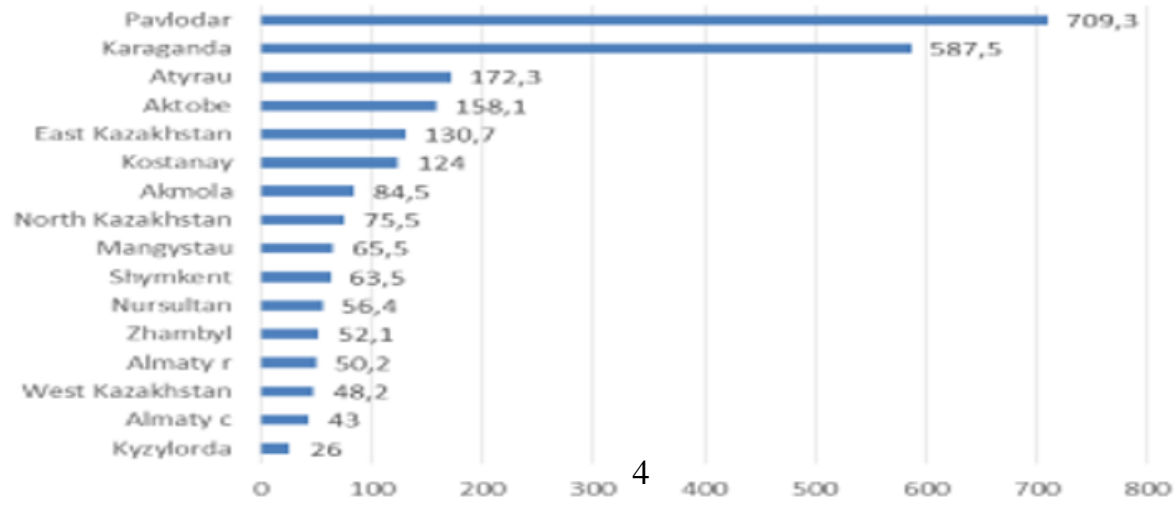


metals to enter water

Fig 2. Air pollutants in the regions of Kazakhstan.

Picture 2 shows that more than half of the total atmospheric pollution is generated in Pavlodar and Karaganda regions due to the concentration of the largest mining enterprises such as Kazakhstan Electrolysis Plant JSC in Pavlodar and ArcelorMittal Temirtau JSC in Karaganda. The development of raw materials sectors is accompanied by intensive use of natural resources, as well as emissions of harmful substances, the consequences of which cause environmental damage even after the liquidation of such industries. In the Republic of Kazakhstan, $70 \%$ of extractive enterprises and primary processing of natural resources are in the hands of foreign companies [6].

The green revolution of the 1960s, which made it possible to use the achievements of the chemical industry to increase productivity in the agricultural sector of the economy, led to the saturation of the market with essential goods, although it did not solve the problem of hunger in individual developing countries. The population is forced to consume food products with an unacceptable level of various chemical additives that stimulate the fertility of the earth and the preservation of food. The use of pesticides in agriculture has begun to take on rampant proportions for the health and life of humankind. A negative consequence was the emergence of new diseases among the population, such as food allergies, cardiovascular diseases, etc.

The most severe consequences of industrialization are observed in developing countries where, for the current benefit of certain social groups, the Earth's bowels are depleted, parks in cities and forests on their outskirts are cut down, and radioactive waste can be buried near settlements for the sake of receiving dubious investments.

Low social standards in these countries are considered and used by external investors as competitive advantages for such investments of material capital. Meanwhile, it is undeniable that material capital can be reproduced in the short term, and decades and centuries are required to revive natural capital.

In addition, material capital is personified, i.e. represents individual or group interests, and natural capital belongs to a number of universal values and its use requires planetary thinking.

By his actions, man influences the structure and quality of nature based on his own consumer interests: he adapts to create his own comfort and at the same time inflicts irreparable damage to it.

\section{The need for new environmental entrepreneurial behavior}

As for the scientific support of actively advancing technical progress, at the initial stage, developments in the search for forms and methods for a more complete mastery of natural resources and its use in order to create material wealth became relevant. At the same time, the most affordable resources such as natural hydrocarbons and minerals were considered, which do not require significant costs for processing and conversion into energy.

This article attempts to reveal the author's vision of the conditions and prerequisites for creating a new entrepreneurship paradigm, which will be based on renewable energy and resource-saving technologies: a model of green economy. As is well known, the essence of entrepreneurial activity is manifested in innovation, in the search for new technologies and managerial approaches in solving emerging contradictions. The modern entrepreneur will have to resolve the contradiction between limited resources and changing consumer preferences without harming Nature. 
In this regard, it should be noted that the oil prices increase in the 1970s gave impetus to the development of new resource-saving technologies. Japan succeeded in it, where the post-war economy was formed on new technologies acquired (licenses, patents, "brains") in Western countries with money received from the USA for permission to deploy military bases on its territory.

After the economic downturn of the 1970s, the recovery phases of the world economy began, thanks to the achievements of the scientific, technological and emerging information revolution.

However, history repeats by virtue of spiral development law: in a new round of 2010-2014, the world is in a new economic crisis, which is generated by the next stage of consumer goods overproduction in developed countries, and overproduction of oil in countries rich in oil resources. An increase in the price for a barrel of Brent crude oil to $\$ 150$ was a "blow" for developed countries, and when it fell to $\$ 47$ in 2015 , countries whose economies are built on economic growth model based on oil export revenues fell into crisis.

The swaying of the global economy leads to the desire of more developed countries to engage in a struggle (war) for new resources markets and finished products marketing. Under these conditions, social and political tension is growing in the regions and in the world as a whole.

Overcoming the crisis for both developed and emerging markets in the development and use of new technologies.

The methodological message in the development of a new reproduction model is the realization that the Earth and the wealth of its bowels are the property of humankind, including its future generations.

Its wasteful consumption by society during the period of industrial development led to the depletion of the entire biosphere, the formation of the noosphere, unfavorable for human life. This is manifested in the growing dependence of the economies of all countries on fluctuations in energy prices, environmental degradation due to emissions of harmful waste from its extraction and processing into the atmosphere, and the emergence of new biological viruses and diseases. In other words, nature takes revenge on man for the "unceremonious invasion".

An organic part of the green economy and the new energy sector is the environmental consumption culture, which is based on the mode of saving limited natural resources and resource conservation.

In this regard, it must be pointed out the economic policy of the last century, fueled by apologists from science, aimed at developing a consumer society in order to expand market demand and stimulate producers. The excesses in consumption began to be regarded in society as an indicator of success. Production and consumption, without commensurate with the damage to natural capital, has become the main contradiction of a post-industrial society.

In the countries of the former Soviet Union, such principles of consumption as saving water, electricity and heat have not taken root. In many respects, the reason for this is the costs of the supply system, which does not provide for accounting and the possibility of regulating consumption. The absence of metering meters and regulators of heat input in the rooms in winter does not allow switching to the saving mode. Modern society has come to a critical threshold of wastefulness.

But nature "does not tolerate" emptiness and imbalance in its content. Many natural disasters, diseases and mutations of the human body are the result of gross, illiterate human intervention.

\section{Results and discussions}


There is a need to create a new model of production and consumption culture, which will expand reproduction while reducing the cost of natural capital.

It became apparent that the only prospect for further development is the transition to environmentally friendly technologies based on renewable natural energy sources and resource conservation.

The new model of sustainable development is called the "green economy". Unlike the brown economy, it is based, firstly, on the use of naturally renewable natural resources: energy from the sun, wind, water, and secondly, on resource-saving technologies.

The green economy, as defined by the United Nations Environment Program (UNEP), is an economy that "enhances human well-being and ensures social justice while significantly reducing environmental risks and its impoverishment." And the United Nations Economic and Social Commission for Asia and the Pacific (ESCAP) defines green economic growth as a political focus that relies on "environmentally sustainable socioeconomic progress to stimulate low-carbon and inclusive social development [7].

It is known that energy is a conservative and most costly industry. First of all, because its material and production base is distinguished by tremendous power, scale and, accordingly, requires high financial costs. Technological renewal of the production base requires gradual, phased measures for the construction of new production sites, equipping with completely new equipment and training new generation specialists with new knowledge and a high working culture.

Kazakhstan's ability to a green economy transition is internally contradictory. On the one hand, there is no domestic processing industry, the country imports up to $80 \%$ of personal goods, goods of I division. Therefore, the creation of a new green economy does not require a long and painful liquidation process, the outdated material production base of brown technologies.

On the other hand, the previous trajectory of non-market economy and low level of industrial development means that the relationship between labor and capital that meets the requirements of a post-industrial society has not been established and adjusted in society. Professional staff, experienced managers, motivation and control mechanisms are the minimum set of initial conditions that should form technological, financial and labor disciplines from scratch, and we will have to "jump" through three turns of the spiral development of industrialized countries that have survived three industrial revolutions.

But it should be recognized that resource opportunities: a highly educated nation, natural reserves and ambitiousness (these national traits are noted by foreign investors and consultants) can allow us to quickly adapt to the new requirements of the global economy.

Moreover, in developed countries, sufficient experience has been accumulated in the transition to a green economy and foreign investors are ready to invest their financial capital in the implementation of the green economy program in Kazakhstan. Competent contracts with worthy investors and monitoring of their implementation by all parties can gradually build a green technology economy. A prudent policy to adapt foreign experience allows Kazakhstan to use its chance in the development and implementation of the state Program for the transition to a green economy.

In the EU countries, the annual turnover of the eco-industry is more than 300 billion euros (2.5\% of GDP), about 3.4 million people (1.5.\% Of all employed) are directly employed in this area. $1 / 4$ of all investments are in green technologies. The indicated progress was achieved, inter alia, thanks to the mobilization of efforts of the EU member states.

In Germany, interest in the green economy arose in the 1980s, when arguments in favor of abandoning a peaceful atom strengthened in German society. From that moment, an active search for an alternative and support for any green initiatives began. "Even at the 
local government level, assistance was provided to those who installed solar panels in their households," said the expert.

Then interest shifted to the land level, and only in the $90 \mathrm{~s}$ - to the federal one. The Law "On Renewable Energy Sources" was adopted by the Bundestag in 2000 and marked the beginning of a sharp increase - since then, the share of renewable energy in the energy balance of Germany has increased by more than 16 percentage points [8].

In India, the Federal Ministry of Renewable Energy was formed, which set the task in the next few years $10 \%$ of the consumed electric power in the country to cover from solar energy. In this regard, it is planned to build 33 power plants, each of which will supply $2.125 \mathrm{MW}$ to the electricity network. The Indian government has set an ambitious task - to achieve the same rapid growth in solar energy in the country, as it was boom in India in the field of computer service development [8].

The actions of mankind aimed at the development of environmentally friendly production as a prerequisite for sustainable development, reduce dependence on natural resources. Ensuring a qualitative improvement of the environmental situation, which the world community is striving for, requires a combination of efforts, actions coordination of countries investing in the green economy. Luxembourg, Iceland, Denmark, Norway and the Netherlands have consistently held high positions in most of the selected green growth parameters and are at the forefront in the transition to eco-entrepreneurship [9].

The following figure reflects the calculation of economic growth taking into account the environmental factor. Given the increasing role of the environmental issue in shaping national wealth, GDP growth is adjusted for pollution. When calculating this indicator, not only classical factors, such as labor and capital, but also the use of natural resources, as well as an index such as environmentally adjusted multi-factor productivity, are taken into account.

This scheme is valuable for determining the factors of economic growth, not only labor and capital are taken into account, but also the level of environmental pollution since an integral component is environmentally-friendly multi-factor performance.
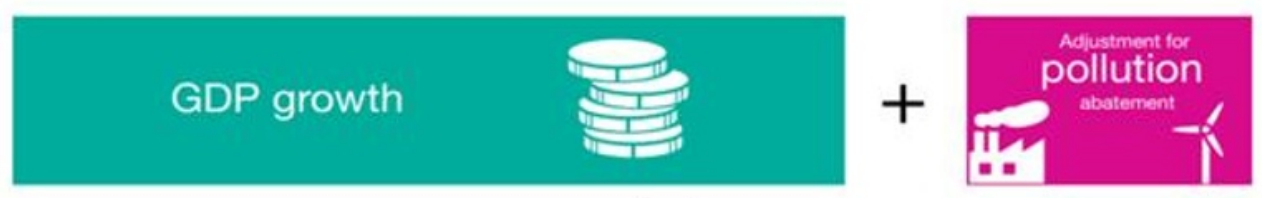

\section{Pollution-adjusted GDP growth}
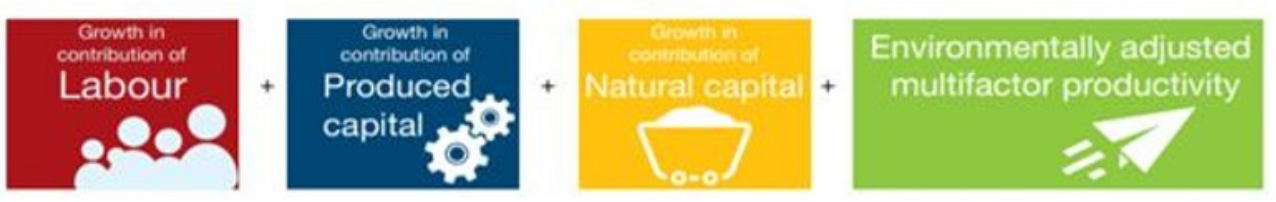

Fig 3. OECD productivity measurement framework

Unfortunately, in developing countries, including Kazakhstan, such a scheme is not used in macroeconomic analysis.

This indicator reflects the share of pollution associated with the release of products with a standard set of input data. 


\section{Conditions for Institutional Transition}

To build a policy for the transition to a green economy, it is first necessary to form the institutional base: a program for a phased transition to a green economy (concept, laws and regulations that do not contradict other laws, as well as institutions that do not overlap each other).

The functioning of many public and private departments and organizations to implement the Kazakhstani Program for the transition to a green economy can lead to the resources dispersal, to the divergence of regulatory documents, and to complicate monitoring and control over the execution of government orders.

Equally important is the upbringing of ecological culture consumption, as well as the training of production and trade specialists to learn new technologies based on resource conservation.

The most difficult task is the staffing of green economy sectors. The most acceptable in the current conditions, in our opinion, is the use of franchising mechanisms in the education system. Franchising in the field of education is associated with the prospects of introducing western management principles, developing creative initiatives of students and young teachers, creating conditions for improving their qualifications, etc.

A feature of the new approach in this integrated structure is seen in the fact that universities will become the leading link initiating innovations in production. At the same time, universities - understudies of foreign "grandparents" can train specialists by organizing internships at enterprises organized on the basis of franchising.

\section{Conclusion}

The natural source of life on Earth is solar energy, which turns into the biochemical energy of living matter, thereby creating a biosphere for human life and activity. Of all the individuals living on Earth, Man during the course of business most actively affects Nature and depletes natural capital. Material capital may be reproduced in the short term, but to revive natural capital decades and centuries are required.

The lingering idea of society that the Earth and its bowels are the main productive force has led to their wasteful exploitation, to the depletion of the entire biosphere, the formation of the noosphere, which is unfavorable for human life.

In addition, the dependence of the global economy on the hydrocarbon market is growing, its stability is being undermined.

Production and consumption, without commensurate with the damage to natural capital, has become the main contradiction of the post-industrial society. Humanity has come to a critical threshold in the unfair use of natural capital, the need to move to a new stage of universal progress.

Kazakhstan, continues to develop according to the model of resource-consuming economies, using technologies that plunder irreproducible natural resources and pollute the environment.

The transition to a green economy requires a rethinking of many methodological approaches in the study of the modern model of reproduction, in which the Earth and its bowels are the main means of production. Depletion of natural capital, environmental pollution undermine the sustainability of the economy. It is necessary to direct the excess profits received from their use of natural resources to create renewable energy. The formation of the ecological culture of the population should become an integral element of the education system.

The transition from a rent-oriented approach in the behavior of market entities to resource-oriented approaches requires adequate knowledge, skills, and competencies. In 
this regard, the role of education and research is growing. It is necessary to create international scientific laboratories and centers in companies and universities of the country.

Reduced pollution can also affect growth rates. Some countries have achieved economic growth due to environmental quality. In particular, this applies to India, Saudi Arabia and China, as well as some OECD countries, such as Turkey, Korea and Mexico $[10]$.

Managers of innovative companies in the real sector, encouraging the principles of a green economy, should pay attention to strengthening their internal enterprise potential by absorbing external knowledge, as well as mechanisms for training relationships at all levels of the production process as the main components of a competitive advantage [11].

The use of franchising in the tandem of education and production can accelerate the structural development of higher education and domestic industry, build a model: "education - science - new technologies - entrepreneurship" [12].

Eco-innovations are primarily designed to qualitatively improve the life of society, but for enterprises it is an extra cost, especially considering the fact that when buying eco product buyer may not even feel any difference that is why government should support those enterprises which are going to follow green economy way [13].

However, taking into account environmental strategies based on the fact that enterprises produce eco-friendly products it can increase the demand for its goods and services as well [14].

Green innovation is a promising area of innovative entrepreneurship. In addition to profit, this activity brings positive effect to maintaining a balanced environment. Opportunity analysis is a decisive factor in the development of innovation in general and green innovation in particular. Systematic innovation and in-depth study of the enterprise's potential underlies the success of innovative eco-entrepreneurship [15].

\section{References}

1. V.I. Vernadskiy. Biosfera. Izbr.soch. 5, 58 (1960)

2. M.L. Myers. The soul of modern man: idea of selfinterest. Thomas Hobbs to Adam Smith, 28 (1983)

3. A.Smith. An Inquiry into the Nature and Causes of the Wealth of Nations, 253 (1962)

4. D.L. Meadows, The limits of growth. Report to the Club of Rome. Electronic resource. http://www.ihst.ru/ biosphere.

5. Germany has become a leader in recycling, Electronic resource https://www.dw.com/, Download date 01.02.2020

6. Air pollutant emissions 2018. Electronic resource, https://stat.gov.kz/, Download date 01.02 .2020

7. Materials of the VII European Conference "Environment for Europe", Astana, 2011. Electronic resource.-WWW ECE / CEP / S / 2011 / L.3. Download date 11/16/15.

8. An analytical review of world experience in developing a green economy. http://dw.de/p/17t6p. 03/07/13

9. Green growth indicators 2017. Highlights. Electronic resource http://www.oecd.org/, Download date 01.02.2020

10. Greening productivity measurement, Electronic resource http://www.oecd.org, Download date 01.02.2020

11. Gema Albort-Morant, Antonio L. Leal-Rodríguez, V. De Marchi, Journal of Knowledge Management, Absorptive capacity and relationship learning mechanisms as complementary drivers of green innovation performance. (2018)

12. B. Kisikov. Franchising in Kazakhstan, 290, (2011) 
13. V. De Marchi. Environmental innovation and R\&D cooperation: Empirical evidence from Spanish manufacturing firms, Research Policy , 41, 614-623 (2012)

14. V. De Marchi, E. Di Maria, S. Micelli. Environmental Strategies, Upgrading and Competitive Advantage in Global Value Chains, Wiley Online Library (2012)

15. P. Drucker. Harvard business review, 169 (2019) 